\title{
O APRIMORAMENTO DAS INSTITUIÇÕES COMO GARANTIA DO EFETIVO ACESSO À JUSTIÇA
}

\author{
Marcio Secco ${ }^{1}$ \\ Juliana Mendes de Oliveira Wagner ${ }^{2}$ \\ Wanderley José Cardoso ${ }^{3}$
}

\section{Resumo}

O acesso à justiça é tradicionalmente compreendido como a possibilidade de judicializar demandas em igualdade de oportunidades e de obter nestes resultados justos. Todavia, reduzi-lo ao poder de litigar o restringe à atuação do poder judiciário e estimula a propositura de ações e o descaso das instituições públicas em garantir direitos humanos e fundamentais administrativamente. A partir desta premissa, o objetivo deste trabalho é demonstrar que a sistemática violação de direitos por parte das instituições públicas que deveriam ter como finalidade garantir os mesmos direitos, acaba por criar sérias dificuldades ao acesso à justiça das pessoas mais vulneráveis. A metodologia utilizada é de abordagem qualitativa, quanto aos procedimentos é bibliográfica e documental e, quanto aos objetivos é explicativa e descritiva. Concluímos que a compreensão tradicional do direito ao acesso à justiça limita o próprio direito e serve de subterfúgio para a omissão das instituições, que, muitas vezes, adotam uma postura protelatória, baseada em negativas excessivamente burocráticas, compelindo o cidadão a buscar por via judicial aquilo a que indubitavelmente faz jus. O presente estudo esclarece que a plenitude do acesso à justiça depende de um conjunto de esforços empreendidos por instituições, mecanismos, pessoas e procedimentos voltados para a efetivação de direitos.

Palavras-chave: Acesso à justiça; Efetividade de Direitos; Instituições justas; Justiça; Poder Judiciário.

\footnotetext{
${ }^{1}$ Doutor em Ética e Filosofia Política (UFSC); Professor Adjunto do Departamento de Filosofia e professor permanente do Programa de Pós-Graduação Stricto-Sensu Mestrado Profissional Interdisciplinar em Direitos Humanos e Desenvolvimento da Justiça. Fundação Universidade Federal de Rondônia. E-mail: msecco@unir.br.

${ }^{2}$ Mestranda em Direitos Humanos e Desenvolvimento da Justiça pela Fundação Universidade Federal de Rondônia; Servidora do Tribunal de Justiça do Estado de Rondônia. E-mail: julianamowagner@gmail.com.

${ }^{3}$ Mestrando em Direitos Humanos e Desenvolvimento da Justiça pela Fundação Universidade Federal de Rondônia; Juiz de Direito no Tribunal de Justiça do Estado de Rondônia. E-mail: wanderley@tjro.jus.br.
} 


\section{INTRODUÇÃO}

Tradicionalmente, o acesso à justiça é compreendido enquanto direito de acesso ao Poder Judiciário e sob esta perspectiva o sistema jurídico deve ser igualmente acessível a todos e deve produzir resultados que sejam individual e socialmente justos (CAPPELLETTI; GARTH, 1988, p. 8). No entanto, essa interpretação limita o próprio direito ao passo que a concretude da justiça não deve depender exclusivamente de uma prestação jurisdicional.

Sob a ótica dos Direitos Humanos, o acesso à justiça deve ser entendido como o direito de ter direitos concretizados. Isso porque, os Direitos Humanos não são meras palavras vazias e devem ser realizados no mundo fático para a plena satisfação do indivíduo e de grupos sociais, razão pela qual o acesso à justiça deve constituir-se como um mediador pelo qual torna-se tangivel o cumprimento e efetivação daqueles.

Embora amplamente debatido no âmbito da filosofia, da sociologia e do direito, o conceito de justiça não é uníssono. Por outro lado, é incontroverso que, em um Estado Democrático, as instituições devem promovê-la de tal modo que haja satisfação ou, pelo menos, aceitabilidade dos atos praticados pelo poder público. Para que isso ocorra, diante das especificidades do nosso modelo de Estado de Direito, o justo é que os direitos humanos e fundamentais sejam observados formal e substantivamente.

A perfectibilização do direito deve, portanto, ser promovida por meio de instituições justas, isto é, instituições que cumprem com o seu papel na efetivação dos direitos dos cidadãos de acordo com suas competências. Contudo, o que se verifica no cenário administrativo atual é que órgãos do Poder Público, ou a ele vinculados, criam obstáculos excessivamente burocráticos e, inclusive, contrários às normas jurídicas, obrigando boa parte da população necessitada a buscar a garantia de seus direitos no âmbito do Poder Judiciário.

Essa forma de atuação é indubitavelmente contrária ao princípio do acesso à justiça e ao próprio Estado Democrático de Direito, uma vez que nega-se aos indivíduos uma ordem jurídica justa, isto é, a um conjunto de instituições que dêem efetividade ao direito e, sobretudo, promova a justiça em sua concepção substantiva.

A partir de uma pesquisa de abordagem qualitativa; quanto aos procedimentos, bibliográfica e documental e; quanto aos objetivos, explicativa e descritiva, demonstramos que a atual forma de atuação das instituições públicas viola tal princípio, impõe ao cidadão à busca por uma tutela jurisdicional e sobrecarrega o Poder Judiciário de "demandas desnecessárias".

Ao final, concluímos que para garantir o direito ao acesso à justiça este deve ser concebido não apenas enquanto acesso ao Poder Judiciário, mas, também, como o acesso a Instituições Justas. 


\section{O SIGNIFICADO DE ACESSO À JUSTIÇA}

O acesso à justiça representa a realização de uma pretensão presente em cada pessoa da sociedade. Todos, individual ou coletivamente, anseiam pela realização de justiça em todos os atos praticados e relações intersubjetivas.

Segundo Cappelletti e Garth, o conceito de acesso à justiça sofreu grandes transformações, decorrentes da mudança de visão dos Estados Liberais dos séculos XVIII e XIX, que até então adotavam uma postura passiva frente os direitos naturais e que refletiam a filosofia individualista da época (1988, p. 9-11).

Quando as relações humanas se intensificaram e adotaram um caráter mais coletivo, exigiu-se do Estado uma atuação mais positiva e garantidora dos direitos substanciais do homem, transformando uma visão individualista dos direitos, refletida somente na declaração destes, para o reconhecimento de direitos humanos fundamentais, dentre eles o efetivo acesso à justiça.

Em regra, este princípio é entendido como a possibilidade de um sistema jurídico acessível indistintamente a todos que dele necessitem, independente de capacidade financeira para tanto. Além disso, modernamente, afeiçoa-se o acesso à justiça com a noção de efetividade do processo, porquanto o poder jurisdicional não se limita mais em apenas dirimir os conflitos apresentados, mas sim, eliminá-los de forma rápida e efetiva,buscando-se a pacificação com justiça e garantindo a equidade entre as partes.

Nesse sentido, nos ensina Teori Albino Zavascki que "o direito fundamental à efetividade do processo que se denomina também, genericamente, direito de acesso à justiça ou à ordem jurídica justa - compreende, em suma, não apenas o direito de provocar a atuação do Estado, mas também e principalmente o de obter, em prazo adequado, uma decisão justa e com potencial de atuar eficazmente no plano dos fatos" (1999, p. 64).

Cappelletti e Garth apresentam a definição que é até os dias de hoje perpetuada pela doutrina. Para os autores, tal direito serve para determinar duas finalidades básicas do sistema jurídico, isto é, 1) o sistema deve ser igualmente acessível a todos; 2) ele deve produzir resultados que sejam individual e socialmente justos (1988, p. 8).

Por outro lado, o que pretendemos apresentar neste trabalho é que o acesso à justiça, dada sua importância enquanto mecanismo efetivador dos demais direitos, não pode se resumir ao acesso ao Poder Judiciário e à possibilidade de ingresso em juízo, mas deve ser compreendido, também, como o acesso a Instituições justas. 


\section{Acesso à Justiça enquanto Direito Humano}

O acesso à justiça como direito humano tem aparecido em várias declarações desde 1948. Entre as principais fontes encontramos a Declaração Universal de Direitos Humanos (1948), que prevê expressamente em seu artigo $8^{\circ}$ que "todo ser humano tem direito a receber dos tribunais nacionais competentes remédio efetivo para os atos que violem os direitos fundamentais que lhe sejam reconhecidos pela constituição ou pela lei"; a Convenção Americana de Direitos Humanos (1969), em seu artigo 254 , também destaca o Acesso à Justiça como um direito a ser garantido por todos os Estados signatários; o Pacto Internacional das Nações Unidas sobre os Direitos Civis e Políticos (1966), por sua vez, preconiza, em seu art. 14, que “Toda as pessoas são iguais perante os tribunais e as Cortes de Justiça”.

Os Direitos Humanos positivados não podem se limitar a uma carta de intenções, ao contrário devem ser realizados no caso concreto para a plena satisfação do indivíduo, de grupos sociais ou da sociedade como um todo. A existência de tais direitos pressupõem, então, que os membros da sociedade cumpram as regras e que o Estado forneça um aparato para garantia do seu cumprimento e efetivação. Este aparato é, em muitos casos, compreendido como sendo exclusivamente o Poder Judiciário. As próprias declarações que citamos acima contribuem para a compreensão do acesso à justiça como direito que tem o Poder Judiciário como único responsável por sua concretização.

Ao passo que o acesso à justiça atua como mediador entre a garantia e a concretização de direitos, este deixa de ser concebido enquanto garantia processual e adquire o status de direito humano.

Cappelletti e Garth pontuam que o acesso à justiça deve ser encarado como um requisito fundamental de um sistema jurídico moderno e igualitário, porque é intrínseca a este a existência de mecanismos que sejam capazes de transcender o direito garantido pela norma à efetividade prática ou que, em caso de negativa, permita a sua reivindicação (1988, p. 11-12).

A Constituição Federal do Brasil, embora também não indique expressamente o instituto, o materializa por meio do princípio da inafastabilidade da jurisdição, segundo o qual a lei não excluirá da apreciação do Poder Judiciário lesão ou ameaça a direito (art. 5o, inc. XXXV, CF/88) e através do direito de petição, que estabelece a possibilidade do cidadão, independente do pagamento de taxas, peticionar aos Poderes Públicos em defesa de direitos ou contra ilegalidade ou abuso de poder (art. 5, inc. XXXIV, “a”, CF/88).

Tais dispositivos deixam clara a preocupação do legislador constituinte originário com a concretização

\footnotetext{
4 "Toda pessoa tem direito a um recurso simples e rápido ou a qualquer outro recurso efetivo, perante os juízes ou tribunais competentes, que a proteja contra atos que violem seus direitos fundamentais reconhecidos pela constituição, pela lei ou pela
} vol.11, no. 04, Rio de Janeiro, 2018.pp. 3173-3192 
dos direitos fundamentais e humanos, não apenas na esfera judicial, mas também por meio das próprias instituições competentes para sua sua materialização. Vale dizer que a Constituição Federal visa, portanto, uma ordem social que, por si mesma, garanta a efetividade de direitos. Essa efetivação é a própria essência do acesso à justiça que não pode ser visto de outra forma, senão, como um direito humano.

\section{As três ondas de Acesso à Justiça}

A obra “Acesso à Justiça” de Cappelletti e Garth (1988), é uma indiscutível referência a respeito dessa temática. Pioneiramente e em uma época em que o acesso a justiça não tinha, ainda que no campo do Judiciário, a amplitude e a compreensão hermenêutica que se tem nos dias atuais, os autores apresentaram três fases sucessivas de movimentos de acesso à justiça que denominaram de ondas.

Os autores apontam que o acesso à justiça era, como já mencionado, concebido apenas como o direito formal do indivíduo agravado de propor ou contestar uma ação e, em razão de demandas sociais, por igualdade material, proteção coletiva e por meios alternativos de solução de conflitos, Cappelletti e Garth apresentam a temática sob a perspectiva de ondas evolutivas e sugerem, ainda, um "novo enfoque", isto é, que tal direito passe a ser concebido, também, como um conjunto de instituições e mecanismos, pessoas e procedimentos utilizados, inclusive, para prevenir disputas nas sociedades modernas.

A primeira onda de acesso à justiça descrita pelos autores é a assistência judiciária para os pobres, isto é, a possibilidade de reivindicar a efetivação de direitos perante o Poder Judiciário por todos indistintamente. Os autores, destacam que possibilitar o ingresso, no entanto, não foi suficiente porque o Estado não adotou qualquer atitude positiva para garanti-lo.

O auxílio de um advogado, embora indispensável, dependia do interesse destes na prestação de serviço voluntário e, portanto, sem contraprestação (munus honorificum). Os autores destacam que mesmo o pioneirismo da Alemanha, em 1919 - 1923, que iniciou um programa de remuneração de advogados para prestar assistência jurídica a quem pleiteasse, não se mostrou eficaz, ao passo que permitia, apenas, que os advogados reavessem as despesas gastas, e não os honorários, do Estado.

Foi nos Estados Unidos, em 1965, com a War on Poverty ("guerra contra a pobreza"), durante o governo do Presidente Lyndon B. Johnson, que se iniciaram reformas mais drásticas no modelo de assistência judiciária, através do Office of Economic Opportunity (OEO), em que o custo dos honorários eram suportados pelo Estado e essa prática se perpetuou pelo mundo em países como a Holanda, a Áustria, a Itália, a Austrália, a França e a

presente convenção, mesmo quando tal violação seja cometida por pessoas que estejam atuando no exercício de suas funções oficiais." (Convenção Americana de Direitos Humanos, art.25, 1969). 
Alemanha (CAPPELLETTI e GARTH, 1988, p. 34).

Assim, frente à dimensão das reformas desencadeadas na época, Cappelletti e Garth apontam três sistemas de prestação de assistência judiciária gratuita, o Sistema Judicare (advogados particulares pagos pelo Estado para litigantes de baixa renda); O Advogado remunerado pelos cofres públicos (serviços jurídicos prestados por escritórios de vizinhança que facilitavam o acesso e minimizavam barreiras de classe, além de viabilizar a busca por direitos de classe de forma individual e coletiva) e; o Sistema de Modelos Combinados (meclava os anteriores e oferecia a escolha entre o atendimento por advogados servidores públicos ou particulares).

No Brasil, a primeira onda ganha consistência com a Lei no 1060, de 05 de fevereiro de 1950, e somente com a entrada em vigor da Constituição de 1988 que assistência judiciária ganhou status de garantia constitucional.

A grande questão da primeira onde é que mesmo os modelos de assistência judiciárias reconhecendo os interesses dos pobres como grupo, outros interesses difusos continuavam a ser ignorados, como a classe dos consumidores e dos defensores do meio ambiente, o que resultou na segunda onda, cujo intuito era realizar esforços para melhorar o acesso à justiça no tocante à representação dos interesses difusos, coletivos e individuais homogêneos, especialmente nas áreas de proteção ambiental e consumeristas (CAPPELLETTI; GARTH, 1988, p. 49).

A preocupação central dessa onda pautou-se em uma transformação da visão tradicional do processo civil, de cunho meramente individualista, para uma concepção social e coletiva, voltada a assegurar a realização dos direitos públicos e de interesses difusos.

Deste modo, a nova percepção do processo levou o legislador e os tribunais a ampliar a legitimação de indivíduos ou grupos para agir na defesa dos interesses difusos, além da ampliação da garantia do contraditório a todos os envolvidos e da obrigatoriedade da decisão para todos os membros do grupo. Nessa onda, surgiu também a figura do advogado de interesse público e as ações coletivas.

A partir do progresso na obtenção de reformas da assistência jurídica e na busca de mecanismos para a representação de interesses públicos e difusos, os autores defendem uma terceira onda renovatória, intitulada de "novo enfoque".

O "novo enfoque" centra sua atenção no conjunto de instituições e mecanismos, pessoas e procedimentos utilizados para processar e mesmo prevenir disputas nas sociedades modernas. Não se trata de abandonar as demais técnicas desenvolvidas na primeira e na segunda onda, mas de tratá-las como apenas algumas das séries de possibilidades para a efetividade do acesso à justiça (CAPPELLETTI; GARTH, 1988, p. 68). 
Esse enfoque sugere a promoção de uma gama de reformas, dentro e fora do sistema jurídico, que vão da criação de órgãos (varas e tribunais) especializados de acordo com a matéria discutida, na própria modificação no direito substantivo para evitar ou facilitar a solução de litígios e na utilização de mecanismos públicos, privados e informais para solução de conflitos (meios alternativos de solução de conflitos).

A terceira onda representa, então, um novo método de pensar o acesso à justiça, isto é, a ideia de que este não se limita à esfera judicial, mas é materializado pelo conjunto de esforços empreendidos por instituições, mecanismos, pessoas e procedimentos voltados para a efetivação de direitos.

\section{INSTITUIÇÕES JUSTAS: A NECESSÁRIA AMPLIAÇÃO DA CONCEPÇÃO DE ACESSO À JUSTIÇA}

O acesso à justiça é, em regra, entendido como o direito de igual acesso ao sistema jurídico, isto é, a possibilidade de todos buscarem tutelas no Poder Judiciário ainda que não disponham de condições financeiras para arcar com as custas e despesas do processo, bem como com advogado particular.

Sob a ótica de Cappelletti e Garth, este deve, também, ser compreendido sob um "novo enfoque" no qual centra sua atenção no conjunto de instituições e mecanismos, pessoas e procedimentos utilizados, inclusive, para prevenir disputas nas sociedades modernas (1988, p. 67). Isso porque, mais que a possibilidade de demandar, este deve ser entendido como a possibilidade do cidadão alcançar seus direitos. Kazuo Watanabe (1998) defende, de igual modo, uma ampla concepção do princípio e especifica que ele deve ser visto como um conjunto de elementos que possibilitem que seu exercício ocorra com qualidade 5 .

É válido salientar que, a ideia de justiça é amplamente discutida no âmbito da filosofia, da sociologia e do direito, não há, no entanto, um consenso doutrinário-filosófico acerca do que a caracteriza. Não obstante, é uníssona a ideia de que, em um Estado Democrático, as instituições devem promover a justiça de tal modo que haja satisfação ou, pelo menos, aceitabilidade dos atos praticados pelo poder públic e que sejam capazes de atribuir-lhes legitimidade.

Para os utilitaristas, as instituições são justas quando alcançam o maior saldo líquido de satisfação dentre

\footnotetext{
${ }^{5}$ Segundo Kazuo Watanabe aponta que o direito de acesso à Justiça é, fundamentalmente, o direito de acesso à ordem jurídica justa e apontam como dados elementares desse direito: (1) o direito à informação e perfeito conhecimento do direito substancial e à organização de pesquisa permanente a cargo de especialistas e ostentada à aferição constante da adequação entre a ordem jurídica e a realidade socioeconômica do país; (2) direito de acesso à justiça adequadamente organizada e formada por juízes inseridos na realidade social e comprometidos com o objetivo de realização da ordem jurídica justa; (3) direito à preordenação dos instrumentos processuais capazes de promover a efetiva tutela de direitos; (4) direito à remoção de todos os obstáculos que se anteponham ao acesso efetivo à Justiça com tais características (1998, p. 128).
} 
os indivíduos que pertencem a determinada sociedade ${ }^{6}$. Rawls (2016), ao apresentar a justiça como equidade como uma alternativa ao utilitarismo, propõe que as instituições serão justas na medida em que atendam aos princípios adotados pelos indivíduos em um momento hipotético que ele denomina de Posição Original, podemos dizer então que, na concepção rawlsiana de justiça, as instituições são justas quando atendem os ideais de justiça escolhidos pelo seu povo.

Habermas (2003), por sua vez, entende que as instituições são justas quanto o poder administrativo é exercido a partir do poder comunicativo, isto é, o poder público exerce suas funções observando o consenso e as negociações obtidas pelos cidadãos comunicativamente.

Como dito, ainda que não haja consenso sobre os elementos que definem o que é justo, a efetividade da justiça decorre da concretização do direito posto, sobretudo direitos humanos e direitos fundamentais, por meio da atuação das instituições públicas de modo geral. Desse modo, limitar o referido princípio ao acesso ao Poder Judiciário é limitar o próprio direito.

$\mathrm{Na}$ concepção aqui abordada, o acesso à justiça é, portanto, a garantia do cidadão de acessar seus direitos independentemente da propositura de uma demanda judicial, mas pela atuação das instituições competentes para sua concretização.

\section{Empecilhos ao acesso à justiça}

Conforme tratado no tópico 1.2, Cappelletti e Garth apresentaram ondas que devem ser superadas para que haja efetivo acesso à justiça. A primeira delas trata da sua concepção mais comum, isto é, da criação de meios que permitam os menos favorecidos financeiramente de demandar em juízo.

Em relação a esta, existe no ordenamento jurídico brasileiro o instituto da gratuidade da justiça para aqueles indivíduos que se declaram pobres na forma da $\operatorname{lei}^{7}$ e para as empresas que comprovarem tal condição. Além disso, a assistência judiciária gratuita é exercida pela Defensoria Pública ou, na sua falta, por advogados dativos.

Quanto a segunda onda, que trata das demandas amplas, de interesse difuso e coletivo, no nosso ordenamento é concretizada por meio da ação civil pública, da ação popular e das diversas ações que permitem a

\footnotetext{
${ }^{6}$ Mill, ao tratar do papel das instituiçôes, destaca que: "[...] a sociedade deve tratar igualmente bem todos os que merecem o mesmo dela, isto é, todos os que merecem o mesmo em termos absolutos. Este é o superior padrão abstrato da justiça social e distributiva, para o qual devem convergir no maior grau possível todas as instituições e os esforços de todos os cidadãos virtuosos (MILL, 2005, p. 102).

${ }^{7} \mathrm{O}$ artigo 98 do Código de Processo Civil (CPC/15) dispõe que: "A pessoa natural ou jurídica, brasileira ou estrangeira, com insuficiência de recursos para pagar as custas, as despesas processuais e os honorários advocatícios tem direito à gratuidade da justiça, na forma da lei".
} 
ampliação da legitimidade extraordinária ativa para proporcionar a judicialização de direitos difusos, no intuito de conseguir resultados em uma ou poucas ações, mas que impactem boa parte da sociedade.

No tocante à terceira onda, que trata acerca do "novo enfoque", podemos vislumbrar, no âmbito judicial, que esta ganhou ampla visibilidade com a entrada em vigor do novo Código de Processo Civil que prioriza a solução de conflitos por meio da conciliação e da mediação ${ }^{8}$. Além destes, a muito tempo são atendidos outros exemplos por eles propostos, como é o caso, por exemplo, da existência dos juizados especiais e de varas especializadas.

Embora ainda sejam necessárias inúmeras evoluções no âmbito do Poder Judiciário para que o acesso à justiça seja, de fato, efetivo, nosso intuito é evidenciar que as instituições públicas estão muito aquém do Poder Judiciário quanto à promoção deste direito.

Não obstante a observância da lei e a promoção dos direitos dos cidadãos seja de responsabilidade de todas as esferas de Poder do Estado, o que se observa é que no legislativo e o executivo existe uma burocracia sistêmica e exacerbada que inviabiliza a sua completude e, por este motivo, é que, muitas vezes, o tratamento justo e a observação dos direitos básicos só se concretiza a partir da judicialização das demandas.

As instituições às quais nos referimos são os órgãos do Poder Público, ou a ele vinculados, a quem compete efetivar ou garantir direitos. Estas instituições, contudo, fazem o contrário disso, ou seja, criam obstáculos excessivamente burocráticos e, inclusive, contrários às normas jurídicas, obrigando quem necessita a buscá-los no âmbito do Poder Judiciário.

Essas formas de atuação são indubitavelmente contrárias ao princípio do acesso à justiça e ao próprio Estado Democrático de Direito, uma vez que nega-se aos indivíduos a efetivação de seus direitos pelas instituições competentes para tanto.

Nonet e Selznick, ao tratar dos sistemas de direito que sucedem-se evolutivamente no tempo com a finalidade de, em síntese, responder demandas sociais específicas, propõem o modelo do direito responsivo, no qual buscam-se objetivos claros e livres da "camisa de força" da autoridade burocrática, isto é, uma organização pós-burocrática que não se preocupa apenas com a regularidade administrativa, mas com a criação de instituições focalizadas em problemas específicos, que planejam-se de modo a aperfeiçoar sua competência cognitiva e que aceitam o processo decisório participativo - cooperação social para a concretização dos direitos garantidos em lei como fonte de conhecimento e autocorreção (NONET; SELZNICK, 2010, p. 152-153).

Não desconhecemos que a atuação do Poder Público depende da observância do princípio da

\footnotetext{
${ }^{8} \mathrm{O}$ art. $2^{\circ}, \mathbb{S} 3^{\circ}$ do $\mathrm{CPC} / 15$ preconiza que: "A conciliação, a mediação e outros métodos de solução consensual de conflitos deverão ser estimulados por juízes, advogados, defensores públicos e membros do Ministério Público, inclusive no curso do processo judicial".
} 
legalidade, mas o excesso de formalismo não pode se sobrepor à efetivação de direitos, sobretudo humanos e fundamentais. A burocracia, em tese, não é um problema, uma vez que esta se presta, segundo a teoria da burocracia, para a organização eficiente e imparcial das instituições, a questão está na sua aplicação equivocada e na sua exacerbação, o que, inclusive, levou a burocracia a ser entendida como uma forma de procedimento que impede soluções práticas, rápidas e eficientes (QUEIROZ, 2013).

O acesso à justiça, de uma forma ampla, passa pela conjunção de diversos fatores, seja de uma forma processual ou extraprocessual, uma visão de direito fundamental e social, com normas condizentes à realidade social, com o Estado garantindo a acessibilidade, não somente ao judiciário, mas, de igual forma, a instituições que promovam uma justiça mais próxima do ideal, seja através de políticas públicas ou através de ausência de restrições a esse acesso por razões meramente burocráticas.

Criar meios para que a sociedade atinja um patamar maior de sensação de justiça é um ideal a ser perseguido por qualquer sociedade para ter-se uma condição social humana digna.

\section{"Burocracia do nível de rua"}

Burocracia do nível de rua é um conceito de Michael Lipsky, mencionado por Silveira e Nardi no artigo "Interseccionalidade gênero, raça e etnia e a Lei Maria da Penha" e que, segundo os autores, permite analisar como as práticas desenvolvidas na linha de frente dos atendimentos à população interferem na execução das políticas públicas, isto é, na efetivação do direito pelas instituições competentes (SILVEIRA; NARDI, 2014, p. 19).

Esse conceito nos permite compreender que a dificuldade na completude do acesso à justiça pelas instituições começa por aqueles que atendem diretamente o público, pessoas que, embora não possuam poderes políticos ou administrativos, têm um alto grau de discricionariedade no desempenho de suas atividades, uma vez que decidem os encaminhamentos burocráticos e, por isso, podem distribuir benefícios ou privilégios de acordo com suas convicções pessoais.

Um exemplo disso, também citado por Silveira e Nardi, é o racismo que se apresenta em determinadas abordagens policiais, em que os agentes públicos tratam de forma diferenciada brancos e negros, essa forma de atuação ocorre tanto no momento da abordagem ostensiva em vias públicas, quanto no atendimento no momento de registros de ocorrência e que, conforme dados obtidos no mencionado artigo ${ }^{9}$, desestimulam a busca de vítimas de violência por justiça.

\footnotetext{
${ }^{9}$ Os autores constataram, a partir de atendimentos e entrevistas com mulheres vítimas de violência e da análise de boletins de ocorrência, o percentual de negras vitimadas é superior ao de negras que registraram ocorrência, 42\% e 36,4\% respectivamente (Silveira, R. S. \& Nardi, H. C.p. 21-22).
} 
Além das questões de interseccionalidade debatidas no estudo apontado, os autores destacam que a burocracia do nível de rua se manifesta sempre que servidores públicos que atuam nos atendimentos à população deixam de fazê-lo com qualidade, isto é, sem prestar o serviço que lhe compete e as informações necessárias e suficientes para que o direito almejado pelo cidadão possa ser concretizado.

O atendente da Secretaria de Saúde, por exemplo, que diz ao cidadão que ele terá que realizar procedimento cirúrgico na rede particular porque o hospital local não o realiza ou deve "buscar seus direitos perante o Poder Judiciário", sem, por outro lado, informar-lhe a respeito da possibilidade de Tratamento Fora do Domicílio ${ }^{10}$ ou mesmo acerca de tratamentos alternativos que dispõe, está negando a este acesso a um tratamento justo. Tal comportamento impede o cidadão de ter seus direitos concretizados de maneira rápida, obrigando-o a demandar judicialmente.

Essas práticas são tão temerária quanto a negativa advinda da autoridade responsável pela instituição, uma vez que viola, além do princípio aqui destacado, os princípios da impessoalidade e da eficiência e, assim como na primeira hipótese, impede a solução administrativa de demandas e estimula a propositura de ações.

\section{Demandas desnecessárias: o estímulo à propositura de ações e solução administrativa de conflitos.}

O termo "demandas desnecessárias" é empregado para casos em que o monopólio judicial é prescindível, diante da evidente possibilidade de solução por meios alternativos ou mesmo quando sequer deveria ter ocorrido a negativa que fundamenta a lide dada a existência patente do direito vindicado.

O que pretendemos abordar aqui é a judicialização que decorre do intuito protelatório das instituições quanto ao cumprimento de obrigações impostas por Lei ou pelo entendimento consolidado na jurisprudência e que, portanto, abarrotam o Poder Judiciário de "demandas desnecessárias" e que, por consequência, dificultam a prestação jurisdicional nos casos em que, de fato, a propositura de uma ação era imprescindível.

Segundo o relatório Justiça em Números do Conselho Nacional de Justiça (CNJ), no ano de 2016 foram propostas 252.641 demandas na matéria de saúde, destas 110.817 versavam sobre fornecimento de medicamentos pelo Sistema Único de Saúde. Já em 2017, os números foram, respectivamente, 217.084 e 108.783. Em que pese a análise neste ponto seja quantitativa, ao se considerar que instituições justas devem buscar a promoção de justiça substantiva, muitos destes casos poderiam ter sido resolvidos administrativamente, ainda que

\footnotetext{
10 "O Tratamento Fora de Domicílio - TFD, instituído pela Portaria nº. 55/99 da Secretaria de Assistência à Saúde (Ministério da Saúde), é um instrumento legal que visa garantir, através do SUS, tratamento médico a pacientes portadores de doenças não tratáveis no município de origem quando esgotado todos os meios de atendimento” (Manual TFD).
} 
para tanto fosse necessário relativizar a lista de medicamentos incluídos nas portarias do Ministério da Saúde.

Considerando o exacerbado o número de ações propostas para pleitear medicamentos, insumos e tratamentos médicos em face do Poder Público foram criados mecanismos voltados para a solução ágil e efetiva no âmbito do Poder Judiciário. Um deles é o Fórum Nacional para o monitoramento e resolução das demandas de assistência à saúde, instituído em 2010 pelo Conselho Nacional de Justiça (CNJ). Em seu período de atuação, segundo o CNJ, o grupo trabalha com o intuito de aperfeiçoar os procedimentos e prevenir novos conflitos na área da saúde, além de discutir soluções para problemas relacionados a medicamentos e fallhas nos serviços do Sistema Único de Saúde (SUS) e planos de saúde privados (CIEGLINSKI, 2018).

Além do Fórum, o CNJ aprovou a Resolução n. 238/2016 para que fossem criados nos Tribunais de Justiça e Tribunais Regionais Federais comitês de saúde com o intuito de adotar medidas para proporcionar a especialização dos magistrados para proferirem decisões mais técnicas e precisas.

Segundo Cieglinski (2018), mesmo com a adoção dessas medidas no âmbito do Poder Judiciário, conforme Relatório de Justiça em Números 2017 (CNJ), houve aumento no número de processos relacionados à saúde, o que nos leva a crer que os esforços partindo de uma única esfera do poder não são suficientes para promover o acesso à justiça de forma efetiva, pois, o Poder Judiciário pode promover mecanismos para julgar com mais precisão e mais agilidade, mas não pode impedir que as ações sejam propostas - ainda que uma das finalidades do Fórum Nacional seja, também, promover esforços nesse sentido ${ }^{11}$.

Uma alternativa à judicialização empregada no Estado de Rondônia é o programa "SUS-MEDIADO", que trata de uma prática inaugurada pela Defensoria Pública do Estado do Rio Grande do Norte em 2012 e adotada pela Defensoria Pública do Estado de Rondônia em 2015 (PIVA; ZAGANELLI, 2017, p. 166).

Ele tem por objetivo resolver conflitos na área da saúde sem que seja necessária a judicialização do caso, através da mediação entre pacientes, Estado e Município. Esse programa já atendeu 7.196 pessoas e impediu, em razão de acordo realizado ou por estar em tramitação, a propositura de 6.694 "demandas desnecessárias" 12.

O que se observa de tais números é que em muitos casos o direito à saúde é negado ao cidadão por motivos meramente burocráticos dentre os quais estão a falta de documentos necessários; a prescrição de um medicamento que, embora esteja previsto nas portarias dos Ministério da Saúde ou na Relação Nacional de Medicamentos Essenciais (RENAME), a CID indicada no receituário médico não corresponde à da portaria; desatualização do laudo; falta em estoque; ausência de laudo que comprove a refratariedade (ineficácia para o

\footnotetext{
${ }^{11}$ O art. 1o da Resolução No 107/2010, ao tratar das finalidades do Fórum Nacional para o monitoramento e resolução das demandas de assistência à saúde, dispõe que: "[...] o Fórum Nacional para o monitoramento e resolução das demandas de assistência à saúde, com a atribuição de elaborar estudos e propor medidas concretas e normativas para o aperfeiçoamento de procedimentos, o reforço à efetividade dos processos judiciais e à prevenção de novos conflitos".

${ }^{12}$ Dados fornecidos pela Defensoria Pública do Estado de Rondônia, atualizados até 22 jun 2018.
} 
trato da enfermidade no paciente) ou intolerância ao fármaco previsto nas portarias ou no RENAME.

Esses motivos tanto são solucionáveis administrativamente que, por intermédio da Defensoria Pública, muitas ações deixam de ser propostas e pela solução obtida no SUS-MEDIADO. Não obstante à existência deste programa, a solução de conflitos ocorre porque, inconformados com a negativa das instituições públicas, os usuários do SUS buscam a Defensoria Pública para solucionar a questão.

O ideal é que o próprio ente responsável pelo fornecimento indique ao cidadão os meios para sanar os vícios, seja pelo agendamento de uma consulta com profissional que suprirá a falta dos laudos, seja pelo auxílio na obtenção dos documentos necessários para a entrega dos fármacos, isto é, o ideal é que os cidadãos fossem amparados por instituições justas e que concretizassem seus direitos.

Outro dado a ser considerado é que, de acordo com relatório do CNJ de 2011 o Instituto Nacional do Seguro Social ocupava o primeiro lugar em uma lista dos 100 maiores litigantes nacionais. O relatório aponta o INSS como parte litigante em 22,33\% do total de processos na Justiça Federal, Justiça do Trabalho e Justiça Estadual. Na Justiça Federal, o INSS era parte em 43,12\% dos processos. Em relatório elaborado por grupo de pesquisadores da Fundação Getúlio Vargas em 2010, entre as razões apontadas para a grande demanda de processos previdenciários destaca-se "a atuação estatal administrativa, formalista e ineficiente, que conduziria a população a buscar a tutela previdenciária pela via judicial" (GABBAY; CUNHA, 2010, p. 35).

A publicação do Anuário da Justiça de 2018 mostra que o problema não diminuiu desde 2011. Segundo os dados apresentados pelo Anuário, cada desembargador federal é hoje responsável por um volume de 13.668 processos, dos quais 40\% são casos relacionados ao Instituto Nacional do Seguro Social (INSS), com destaque para pedidos relativos a auxílio-doença e aposentadoria por invalidez, que representam 47\% deste montante (CONSULTOR JURÍDICO, 2018, p. 10 e 24). Isso torna o grande número de recursos envolvendo o INSS o maior responsável pelo acúmulo e, por consequência, pela morosidade do judiciário nos cinco tribunais regionais federais.

Como exemplo disso podemos citar um dos acórdãos analisados nesta pesquisa (TJ/RO, AC n. 0020370-57.2009.822.0014), no qual o autor da ação sofreu acidente de trabalho (fratura exposta no tornozelo direito), que resultou em restrições definitivas para o exercício da atividade de pedreiro. Tal fato culminou na concessão de auxílio-doença ( $91 \%$ do salário de benefício) e, após a consolidação da condição incapacitante, o INSS substituiu o benefício auxílio-acidente (50\% do salário de benefício) ao argumento de que a incapacidade era apenas parcial e, portanto, o beneficiário era passível de reabilitação. No entanto, trata-se de pessoa em idade avançada (56 anos), com baixa escolaridade ( $1^{\circ}$ grau completo) e que durante toda a sua vida trabalhou como pedreiro.

Ocorre que a jurisprudência dos tribunais de superposição é pacífica no sentido de que a concessão da vol.11, n. 04, Rio de Janeiro, 2018.pp. 3173-3192 
aposentadoria por invalidez deve considerar não só os elementos previstos no art. 42 da Lei n. 8.213/91, mas também aspectos socioeconômicos, profissionais e culturais do segurado, ainda que o laudo pericial tenha concluído pela incapacidade apenas parcial para o trabalho.

Isso porque, não é razoável exigir de um trabalhador braçal, em idade avançada e sem qualificação profissional, que se reabilite em uma nova atividade, diante da possibilidade de que isso the reduza a condição de miserabilidade em face das exigências do mercado de trabalho.

No caso mencionado, a 2a Câmara Especial do Tribunal de Justiça de Rondônia concedeu a aposentadoria por invalidez ao autor, ao fundamento de que "em face das limitações impostas pela doença incapacitante (impossibilidade de exercer a profissão de pedreiro), baixo grau de escolaridade ( $1^{\circ}$ grau completo) e a idade avançada (56 anos), seria ilógico defender a inserção do apelado no concorrido mercado de trabalho, para iniciar uma nova atividade profissional capaz de lhe garantir a subsistência, sobretudo em razão de sempre haver desempenhado a atividade de pedreiro".

O relatório do CNJ - Justiça em Números - aponta que entre 2014 e 2017 foram propostas 61.626 ações classificadas pelos Tribunais como "Aposentadoria por Invalidez Acidentária”. Além dessas, no mesmo período, foram propostas 10.918.319 novas demandas acerca de "Direito Previdenciário", dentre as quais 8.525.091 versavam sobre "Benefícios em espécie".

Não obstante a análise destes números seja quantitativa e não nos permita avaliar a procedência dos pedidos formulados, pelos casos analisados no âmbito do TJRO, é patente a atuação excessivamente burocrática do INSS que se recusa a alinhar as decisões administrativas ao que já é há muito tempo pacífico na jurisprudência, obrigando, assim, que os segurados busquem tutela jurisdicional e aguardem, por anos, a solução do seu impasse. No caso utilizado como exemplo a ação foi proposta no ano de 2009 e o trânsito em julgado da decisão que concedeu o benefício ocorreu apenas em 2017, ou seja, 8 anos até que o direito do beneficiário fosse efetivado.

Utilizamos o exemplo da saúde pública e da previdência social, mas o mesmo ocorre em diversos âmbitos, como por exemplo, em casos de fornecimento de energia elétrica, de execuções fiscais propostas após a prescrição do crédito tributário, dentre outras.

Diversas demandas desnecessárias são promovidas diariamente e o intuito dos autores destas, muitos assistidos pela Defensoria Pública e beneficiários da Gratuidade da Justiça, não é propor uma ação, mas obter um direito que indubitavelmente possuem.

O que torna a necessidade de demandar evidente é a ausência de uma atuação hábil e suficiente para a promoção de justiça substantiva e de instituições públicas que não se orientem tão somente por ditames exacerbadamente burocráticos e de intuito meramente protelatório, fazendo com que conflitos que poderiam ser facilmente resolvidos administrativamente, sejam levados ao Poder Judiciário na forma de ações desnecessárias 
que o abarrotam e contribuem para a morosidade da prestação jurisdicional.

\section{JUSTIÇA SOCIAL: A EFETIVAÇÃO DOS DIREITOS SOCIAIS ATRAVÉS DO ACESSO A INSTITUIÇÕES JUSTAS}

A abordagem que fizemos até aqui foi para elucidar que o acesso à justiça não se restringe ao acesso ao Judiciário, mas abrange também - ou até mesmo sobretudo - ao acesso a instituições justas. Essa restrição hermenêutica limita o referido princípio e serve, inclusive, como subterfúgio para a omissão das instituições, que, muitas vezes, adotam uma postura protelatória, com base em negativas excessivamente burocráticas, de modo que o cidadão se vê compelido a buscar a via judicial.

Embora não exista um consenso filosófico-doutrinário a respeito do que, de fato, seja justiça, Rawls ao tratar da prioridade do justo sobre o bem - em contrapartida a ideia utilitarista de que a justiça é medida a partir do maior grau de satisfação (bem) possível - esclarece que as inúmeras doutrinas abrangentes, isto é, concepções pessoais de cada um, devem, ainda que irreconciliáveis entre si, ser compatíveis com o modelo político adotado.

Isso significa dizer que, não obstante às percepções individuais de cada cidadão, no nosso modelo de Estado Democrático de Direito, o justo é que os direitos mais básicos do homem, isto é, os direitos humanos e fundamentais, sejam observados formal e substantivamente por todas as Instituições do Estado. O acesso ao poder judiciário como forma de garantia de um direito deveria ser concebido como medida extraordinária, e não como procedimento normal a todos que buscam pela efetivação de direitos.

Diante disso, podemos afirmar que são justas as instituições que cumprem com o seu papel na efetivação dos direitos dos cidadãos de acordo com suas competências.

Nos arriscamos a dizer então, que a justiça social se concretiza a partir da efetivação dos direitos sociais e que o acesso à justiça - instituições justas mais o poder judiciário - é o mediumpara a obtenção daquela.

Para tanto, a sociedade deve ter ciência e compreensão de seus direitos, bem como de novas leis e seus impactos. A lei, por sua vez, deve ater-se, mediante a atividade legislativa, à realidade da sociedade, com as devidas atualizações, representando legalmente o que esta tem como expectativa sobre cada assunto, observados, ainda, os direitos das minorias. Para recepcionar as demandas da sociedade - sejam as coletivas ou individuais - o judiciário deve estar pronto para o atendimento, com uma estrutura organizada, e deve adequar a aplicabilidade do direito à realidade social. E, por fim, as instituições públicas devem esforçar-se por dar efetividade ao direito posto independente de prévia ordem judicial.

O acesso à justiça não deve ter impedimentos, sejam eles decorrentes de obstáculos econômicos, sociais, processuais ou, principalmente, decorrentes meramente do excesso de burocracia criado pelas instituições 
públicas. Ousamos dizer que um Estado que não dê efetividade ao acesso à justiça não se respalda como democracia, porque é intrínseco a esta a necessidade de efetivá-lo, uma vez que é somente dessa forma que se torna possível o exercício do direito e, por consequência, a realização da própria justiça.

Desse modo, o direito ao acesso à justiça deve ser uma busca incessante do Estado, em diferentes meios e em todos os Poderes, no intuito de, assim e somente assim, propiciar e praticar corretamente a democracia.

\section{CONCLUSÃO}

O Poder Judiciário é frequentemente utilizado para a correção da omissão das demais esferas de poder. Isso ocorre por dois fatores, o primeiro é que as Instituições Públicas, conhecedoras dos direitos que os cidadãos têm, sejam eles decorrentes da lei ou de entendimento consolidado na jurisprudência, utilizam-se de argumentos excessivamente burocráticos para protelar o cumprimento de suas obrigações, compelindo aqueles a buscar tutela judicial. Em segundo lugar, em razão do engessamento da legislação, este tornou-se, em razão do ativismo judicial, um campo para a promoção de justiça substantiva.

Entendemos que essa prática decorre da compreensão de que o acesso à justiça limita-se ao acesso ao sistema judicial, isto é, entende-se que este princípio garante ao cidadão o direito de ingresso, de isonomia processual e de obter, em tempo razoável, resultados justos e que se efetivem na prática.

Limitar o acesso à justiça a tal esfera, o limita enquanto direito humano, ao passo que os direitos - de um modo geral, mas sobretudo humanos e fundamentais - devem sair do campo da abstração e isso só é possível se o acesso à justiça funcionar como um mediador entre garantia e concretização.

O acesso à justiça é, portanto, uma ferramenta pela qual o exercício dos direitos se torna possível e ele deve ser observado em todas as esferas de Poder, seja no Poder Judiciário, seja por meio de instituições que cumpram com suas competências e tenham como ideal a promoção de justiça, isto é, por meio de instituições justas.

Como principal contribuição deste estudo, é possível concluir que o acesso à justiça não pode se restringir ao acesso ao Poder Judiciário, ao contrário, este deve funcionar como um mecanismo que garanta a efetivação de direitos em todas as esferas de Poder. Via de regra, os cidadãos, sobretudo os mais vulneráveis, são obrigados a recorrer ao sistema judicial, abarrotando-o de "demandas desnecessárias", ou melhor, de casos em que, a partir da atuação de instituições justas, poderiam ser solucionados administrativamente.

A complexidade do acesso à justiça como um direito exige que tomemos sua efetivação de um ponto de vista mais amplo do que apenas como tutela jurisdicional. Torna-se necessário considerar a ação do conjunto de instituições públicas, que podem figurar como potenciais ou atuais violadoras de direitos, como parte do processo 
de realização plena do acesso à justiça. Sem que tomemos as instituições públicas violadoras para além do poder judiciário como parte do problema da concretização do acesso à justiça, dificilmente conseguiremos garantir este direito a todos.

Conclui-se, portanto, que o acesso à justiça impõe ao Estado um conjunto de reformas administrativas que garantam a diminuição das violações por parte de suas instituições como meio para minimizar o montante de ações contra o próprio Estado, permitindo ao Poder Judiciário ser mais célere e prestar um melhor serviço aos cidadãos.

\title{
THE ENHANCEMENT OF THE INSTITUTIONS AS GUARANTY FOR AN EFFECTIVE ACCESS TO JUSTICE
}

\begin{abstract}
Access to justice is traditionally understood as the possibility of integrating demands into a judicial system aiming at equal opportunities and at achieving fair results from these demands. However, reducing the access to the power of litigation restricts it to the operation of the judiciary. Besides this action encourages the claiming to the courts and the neglect of other public institutions relating to the guarantees of fundamental human rights. Based on this premise, the aim of this work is to demonstrate that the systematic violation of rights by public institutions, which should guarantee the same rights, ends up creating serious difficulties for the most vulnerable people to have access to justice. We use a qualitative approach and the procedures we take are bibliographical and documentary; the objectives are explanatory and descriptive. We conclude that the traditional understanding of the right of access to justice limits the right itself and is used as an excuse for the omission of institutions, which often adopt a postponing attitude, based on excessively bureaucratic procedures. This compels the citizens to look for the fulfillment of the rights they undoubtedly have, through justice. Moreover, our study clarifies that full access to justice depends on a set of efforts undertaken by institutions, mechanisms, people and procedures aimed at the realization of rights.
\end{abstract}

Keywords: Acces to Justice; effectiveness of rights; Fair Institutions; Justice; Judiciary. 


\section{REFERENCIAS BIBLIOGRÁFICAS}

ALVIM, J.E. CARREIRO. Teoria Geral do Processo. 19a Ed. Rio de Janeiro: Forense, 2014.

CONSULTORJURÍDICO. Anuário da Justiça Federal - Trabalho interno. São Paulo, 2018.

BRASIL. Constituição Federal de 1988. Disponível em: http://www.planalto.gov.br/ccivil_03/constituicao/constituicaocompilado.htm. Acesso: 23 set. 2018.

Lei n. 13.105 de 16 de março de 2015. Código de Processo Civil. Disponível em: http://www.planalto.gov.br/ccivil_03/_Ato2015-2018/2015/Lei/L13105.htm. Acesso: 14 jul. 2018.

Conselho Nacional de Justiça. Justiça em números - Demandas por classe e assunto. Disponível em: https://paineis.cnj.jus.br/QvAJAXZfc/opendoc.htm?document=qvw_l\%2FPainelCNJ.qvw\&host=QVS\%40ne odimio03\&anonymous=true\&sheet=shResumoDespFT. Acesso em 21 set. 2018.

Conselho Nacional de Justiça. Provimento n. 38/2014. Disponível em: http://www.cnj.jus.br/images/stories/docs_corregedoria/provimentos/provimento_38.pdf. Acesso em 12 jul. 2018.

Conselho Nacional de Justiça. Provimento n. 46/2015. Disponível em: http://www.cnj.jus.br/buscaatos-adm? documento=2966. Acesso em 12 jul. 2018.

Conselho Nacional de Justiça. Resolução n. 107/2010. Disponível em: http://www.cnj.jus.br/buscaatos-adm?documento=2831 http://www.cnj.jus.br/programas-e-acoes/forum-da-saude. Acesso em 13 jul. 2018.

Conselho Nacional de Justiça. Resolução n. 238/2016. Disponível em: http://www.cnj.jus.br/buscaatos-adm? documento=3191. Acesso em 14 jul. 2018.

Superior Tribunal de Justiça. AgInt nos EDcl no AREsp 884666 / DF. Disponível em: https://ww2.stj.jus.br/processo/revista/inteiroteor/?num_registro=201600689703\&dt_publicacao=08/11/20 16. Acesso em 20 jul. 2018.

Superior Tribunal de Justiça. AgRg no AREsp 35.668/SP. Disponível em: https://ww2.stj.jus.br/processo/revista/inteiroteor/?num_registro=201101923149\&dt_publicacao=20/02/20 15. Acesso em 21 set. 2018.

Supremo Tribunal Federal. AgRg no AREsp n. 180362. Disponível em: https://ww2.stj.jus.br/processo/revista/inteiroteor/?num_registro=201201033750\&dt_publicacao=16/08/20 16. Acesso em: 13 jul. 2018.

Supremo Tribunal Federal. RE 855178 RG. Disponível em: 
http://redir.stf.jus.br/paginadorpub/paginador.jsp?docTP=TP\&docID=8015671. Acesso em: 14 jul. 2018.

CAPPELLETTI, Mauro; Garth, Bryant. Acesso à Justiça. Porto Alegre: Fabris, 1988.

CIEGLINSKI, Thaís. Judicialização da saúde: iniciativas do CNJ são destacadas em seminário no STJ. Disponível em: http://www.cnj.jus.br/noticias/cnj/86891-judicializacao-da-saude-iniciativas-do-cnj-sao-destacadas-emseminario-no-stj. Acesso em 13 jun. 2018.

GABBAY, D. M. e CUNHA, L. G. (2010). Diagnóstico sobre as causas de aumento das demandas judiciais cíveis, mapeamento das demandas repetitivas e propositura de soluções pré-processuais, processuais e gerenciais à morosidade da Justiça. Disponível em: http://cnjj.jus.br/images/pesquisasjudiciarias/Publicacoes/relat_pesquisa_fgv_editall_2009.pdf. Acesso em 23 set. 2018.

HABERMAS, Jurgen. Direito e Democracia: entre facticidade e validade. Vol 1.2 ed. Rio de Janeiro: Tempo Brasileiro, 2003.

MILL, John Stuart. Utilitarismo. Porto: Porto Editora, 2005.

MORAIS, Hosana. SUS Mediado atende 810 pessoas e reduz 90\% dos processos de saúde. G1 RO. Rondônia. 9 jan. 2017. Disponível em: http://gl.globo.com/ro/rondonia/noticia/2017/01/sus-mediado-atende-810pessoas-e-reduz-90-dos-processos-na-saude.html. Acesso em: 12 jul. 2018.

NONET, Philippe; SELZNICK, Philip. Direito e sociedade: a transição ao sistema jurídico responsivo. Rio de Janeiro: Revan, 2010.

ORGANIZAÇÃO DAS NAÇÕES UNIDAS. Declaração Universal de Direitos Humanos. Disponível em: https://nacoesunidas.org/direitoshumanos/declaracao/. Acesso em: 20 set. 2018. Pacto Internacional sobre os Direitos Civis e Políticos. Disponível em: http://www.planalto.gov.br/ccivil_03/decreto/1990-1994/d0592.htm. Acesso em 23 set. 2018.

ORGANIZAÇÃO DOS ESTADOS AMERICANOS. Convenção Americana de Direitos Humanos. Disponível em: https://www.cidh.oas.org/basicos/portugues/c.convencao_americana.htm. Acesso em: 23 set. 2018. 
PARÁ. Ministério Público do Estado do Pará. Manual TFD. Disponível em: https://www2.mppa.mp.br/sistemas/gcsubsites/upload/79/instrucoes_TFD.pdf. Acesso em 14 jul. 2018.

PIVA, Érica Bianchi; ZAGANELLI, Margareth Veti. Judicialização da saúde e a obtenção de medicamentos de alto custo: à procura de uma contenção saudável. Revista Eletrônica de Direito do Centro Universitário Newton Paiva, Belo Horizonte, n.33, p. 156-172, set./dez. 2017. Disponível em: http://blog.newtonpaiva.br/direito/wpcontent/uploads/2018/03/DIR33-10.pdf. Acesso em: 14 jul. 2018.

QUEIROZ, Isis. Burocracia X Eficiência: O princípio do formalismo moderado como ferramenta de eficiência na Gestão Pública (2013). Disponível em: https://isisqueiroz.jusbrasil.com.br/artigos/112105696/burocracia-xeficiencia-o-principio-do-formalismo-moderado-como-ferramenta-de-eficiencia-na-gestao-publica. Acesso em 05 jul. 2018 .

RAWLS, John. Uma teoria da justiça. 4 ed. São Paulo: Martins Fontes, 2016.

RONDÔNIA. Tribunal de Justiça do Estado de Rondônia. Apelação n. 0020370-57.2009.822.0014. Disponível em: https://www.tjro.jus.br/apsg/pages/DetalhesProcesso.xhtml. Acesso em: 23 set. 2018.

SILVEIRA, R. S.; NARDI, H. C. (2014). Interseccionalidade gênero, raça e etnia e a lei Maria da Penha. Psicologia \& Sociedade, 26(n. spe.), 14-24.

TORRES, Ana Flavia Melo. Acesso à Justiça. In: Âmbito Jurídico, Rio Grande, III, n. 10, ago 2002. Disponível em: http://www.ambito-juridico.com.br/site/index.php?n_link=revista_artigos_leitura\&artigo_id=4592. Acesso em jul 2018.TORRES, Ana Flavia Melo. Acesso à Justiça. In: Âmbito Jurídico, Rio Grande, III, n. 10, ago 2002. Disponível em: http://www.ambitojuridico.com.br/site/index.php?n_link=revista_artigos_leitura\&artigo_id=4592. Acesso em 14 jul. 2018.

ZAVASCKI, Teori Albino. Antecipação de tutela. 2 ed. São Paulo: Saraiva, 1999.

Trabalho enviado em 03 de novembro de 2018 Aceito em 05 de novembro de 2018 